\title{
化学纪录片
}

新的科普形态

张曾栋 ${ }^{1}$, 莫尊理 2 ,

1 西北师范大学教育学院, 兰州 730070

2 西北师范大学化学化工学院, 兰州 730070

摘要: 以化学科普为例, 探讨纪录片和化学纪录片的内涵及其发展历程。从内容、形式、特色等几个角度, 对几部 口碑较好、质量上乘的化学科普纪录片进行分析。总结归纳化学纪录片的物质价值和精神价值, 展望我国科普事业 的前景, 对未来化学科普纪录片的发展提出了一些简单的建议。

关键字: 化学纪录片; 价值; 科普

中图分类号: G64; O6

\section{Chemical Documentary: A New Form of Science Popularization}

\author{
Zengdong Zhang ${ }^{1}$, Zunli Mo ${ }^{2, *}$ \\ ${ }^{1}$ College of Education, Northwest Normal University, Lanzhou 730070, China. \\ ${ }^{2}$ College of Chemistry and Engineering, Northwest Normal University, Lanzhou 730070, China.
}

\begin{abstract}
This paper takes the science popularization of chemistry as an example to discuss the connotation and development process of documentary, particularly chemistry documentary. From the aspects of content, form and characteristics, this paper analyzes several chemical popular science documentaries with good reputation and high quality. The material and spiritual values of chemical documentaries are summarized, the prospect of science popularization in China is prospected, and some simple suggestions for the development of chemical science documentaries in the future are put forward.
\end{abstract}

Key Words: Chemical documentary; Value; Science popularization

科普工作是一项长期而有意义的事业, 事关未来国民科学素养的健康发展。然而由于种种原 因, 科普工作一直未能得到应有的重视。2016 年习近平总书记在全国科技创新大会上发表了关于科 学普及的重要讲话之后, 科普工作的地位得到了空前的提高。化学是一门既古老又现代的学科, 为 人类创造了无数的物质财富和精神财富, 然而公众对化学仍旧存有一些负面的刻板印象。因此在各 种科普工作中, 化学科普尤为必要和关键。过去的科普载体主要是以科普书籍为主, 当今社会生活 节奏加速, 快餐文化盛行, 风格轻松愉快的科普纪录片就更加受到观众的青睐。以往学者对科普图 书的相关研究较多, 然而在科普纪录片方面的论述尚属空白。笔者以化学科普纪录片为切入点, 对 其内涵和价值进行初步的探讨。

收稿: 2021-01-11; 录用: 2021-02-08; 网络发表: 2021-03-09

“通讯作者, Email: mozl@163.com

基金资助：国家自然科学基金(51262027); 甘肃省科技支撑项目(1104GKCA019) 


\section{1 纪录片和化学纪录片}

关于什么是纪录片, 有多种说法。其中有学者提出纪录片 “是对某一政治、经济、文化、军事 或历史事件作纪实报道的非虚构的电影或录像节目” [1]。1994 年日本 NHK 放送文化研究所做了一 次问卷调查, “是否存在一般意义上纪录片的定义？”，88\%的受调查者认为纪录片没有一般意义的 定义。无独有偶, 在一些欧美国家的类似调查中, 也得出了相同的结论 ${ }^{[2]}$ 。台湾国立艺术学院音像记 录研究所副教授李道明曾说, “我在台湾教学生电影课的时候, 往往会在课程开始前问学生什么是纪 录片, 让他们给纪录片下定义, 经过一年左右的课程, 我又在最后一堂课上, 再请他们给纪录片下 定义。结果在刚开始的时候, 学生往往自信地认为什么是纪录片, 但到了学习结束的时候, 对于什 么叫纪录片就感觉越来越糊涂。因为他们在一年时间里, 了解了一百年左右电影史的发展, 特别是最 近一二十年西方纪录片的发展以后, 发现很难再简单地定义什么叫纪录片 ${ }^{[3]}$ ”。《2019 年中国纪录片 发展研究报告》从纪录电影、电视纪录片、新媒体纪录片、纪录片产业、纪录片传播多个维度对如 今的中国和世界的纪录片发展情况进行了深入而细致的剖析, 从中可以发现无论是关于选题、技术、 制作团队、传播方式还是产业运营, 和过去相比都形成了新的态势 [3]。由此可见, 随着时代的发展, 纪录片的内涵和外延发生了深刻的变革, 过去的范式已无法满足实际的需要。如今, 科学纪录片在 纪录片市场大放异彩, 受到了广泛关注。在众多作品中, $\mathrm{BBC}$ 的纪录片品质最高、口碑最好、影响 最大。科学纪录片兼具科学的严谨求真和人文的休闲娱乐, 是老少皆宜的科普素材。“科技创新、科 学普及是实现创新发展的两翼, 要把科学普及放在与科技创新同等重要的位置。没有全民科学素质 普遍提高, 就难以建立起宏大的高素质创新大军, 难以实现科技成果快速转化。” 䜣平总书记在 “科 技三会” 上的这一重要讲话, 对于在新的历史起点上推动我国科学普及事业的发展, 意义十分重 $大^{[4]}$ 。化学科普是一项长期的、复杂的、艰巨的社会教育工程, 对于促进社会和谐、提升民众生活品 质具有重要意义 ${ }^{[5]}$ 。化学科普作为科普的一个类型, 化学纪录片作为科学纪录片的一个分支, 其提 高全民科学素养的价值是母庸置疑的。

\section{2 化学纪录片的价值}

\section{1 知名度高的化学纪录片}

如今市面上关于化学的纪录片数量不少, 呈现百花齐放之态。其中口碑较好的有《美丽化学》、 《我们需要化学》、BBC 《化学史》、《现代炼金术士一一英国皇家学会 2012 圣诞讲座》、《麻省理工 公开课: 魔术背后的化学》、《门捷列夫很忙》。

《美丽化学》是中国科学技术大学和清华大学出版社联合制作的一个科普项目, 用百微镜头记 录化学反应, 分为 24 集。在超高倍镜头下, 司空见惯的化学反应化成了光与影的交响乐, 原子分子 的圆舞曲, 让观众感叹大自然的鬼斧神工, 充满了动态的和谐之美。凭借独特的创意和优良的制作, 该 片在国内外收到了广泛赞誉和高度评价。

《我们需要化学》是上海教育电视台推出的系列科普专题片, 共有 6 集。分别讲述了 “化学的起 源” “化学与人类饮食” “化学与材料科学” “化学与生命科学” “展望未来化学” 等几个主题。当前社 会存在着一些反化学的声音, 制造化学的负面新闻, 过分夸大化学的危害, 对化学的贡献视而不 见, 避而不谈。甚至在央视的广告中都出现了 “我们痛恨化学” 这样的字眼, 由此可见, 国民的化学 素养尚有待提高, 对公众进行化学科普迫在眉睫、势在必行。《我们需要化学》整部剧深入浅出, 轻 松活泼, 将生活中一些容易被忽视的小细节还原为深刻的化学问题, 可谓是一沙一世界, 一叶一菩提。

$\mathrm{BBC}$ 《化学史》共有 3 集, 虽然篇幅较短, 但是内容却很丰富。其时间线从炼金术时期跨度到现 代化学时期, 内容从炼金术士对炼金术的摸索发展到如今科学家对高科技材料的研发。该片可以称得 上是包罗万象, 麻雀虽小、五脏俱全。通过观看本片, 观众可以对化学学科的发展历程有一个较为全 面的认识。现代化学绝不是仅凭炼金术的简单拼凑, 就能够凭空产生, 辉煌灿烂的现代化学成就背后, 是无数化学家对化学事业的孜孜追求, 是他们心血和智慧的结晶, 是人类顶尖思想的具现化。 
《门捷列夫很忙》是央视于 2020 年重磅推出的一款科普纪录片, 共有 5 集。其内容全部取材于 大众日常的衣食住行。虽然以门捷列夫为名, 但是在剧情中, 门捷列夫只是以动画形象作为内容切 换的衔接和过渡出现。相较于以上几部纪录片, 本记录片更加符合中国观众的胃口, 诙谐幽默的台 词, 设计精巧的实验, 生动有趣的剧情, 牢牢地掌控住观众的猎奇心理, 对提高全民科学素养起到 了很大的作用。

\section{2 化学纪录片的价值}

\subsection{1 时代使命一一化学科普工作的必然要求}

要实现中华民族的伟大复兴, 就必然要求青年们具备实现梦想的能力, 其中关键能力之一就是 科技创新。千里之行始于足下, 科技创新无法通过拍拍脑袋、灵光一现就能够无中生有。只有科学 工作者沉下心来, 用心钻研, 努力奋斗, 科技创新的种子才有可能生根发芽, 长成苍天大树。每个 孩子都拥有各自不同的潜力, 具备无限多的可能。然而很多天资聪颖的儿童由于在童年时期缺少科 学启蒙, 遗憾地与科学之路失之交臂。习总书记将科普工作的定位, 上升到了和科技创新一样的高 度, 正是给每个孩子一个挖掘自身科学潜能的机会, 通过科普真正认识到自己在科学方面的兴趣和 能力。正所谓兴趣是学生最好的老师, 学生对化学产生了浓厚的兴趣, 自然会全力以赴地努力学习。

\subsection{2 历史呈现一一化学科普工作的应有之义}

历史是过去的现实, 现实是未来的历史。对历史的每一次回眸, 都是一次初心的吒问、精神的 洗礼、思想的升华。只有不忘来路, 才能走好正路, 才能开辟新路 ${ }^{[6]}$ 。习总书记曾经说过, “历史是 最好的教科书, 在科学教育、科学普及的领域中, 科学史也发挥着至关重要的作用”。在很多教科书 或者其他教辅资料中, 选用的科学史往往是辉格史, 即以现代科学观去评判过去的人所做的科学工 作。例如大名鼎䖝 “燃素说”, 很多教师谈到燃素说, 往往是采取一棍子打死的态度一燃素说是 毫无科学根据, 一无是处的谬论。以今天的眼光来看, 燃素说当然不是科学, 但是在化学学科漫长的 发展历史中, 燃素说的确做出了它独特的贡献。燃素说在当时具有比其他理论更加明显的优点一一理 论本身较为简单, 而且可以成功解释一些化学现象。根据实证主义科学观, 燃素说在当时完全可以 称得上是一种科学。后来拉瓦锡在总结前人经验的基础上创立了氧化说, 终结了燃素说, 这是一个 相当长久的过程, 如果没有燃素说的坚定支持者舍勒和普利斯特利前期工作的铺垫, 拉瓦锡也无法 从中找到灵感, 发现燃素说的漏洞并建立新的理论。一切过往, 皆是序章。失败的历史也有着它特 殊的价值和存在的意义, 失败乃成功之母, 正是有了这些失败的经历, 科学的每一次进步就显得更 加弥足珍贵。

\subsection{3认识化学一化学科普工作的终极追求}

马克思主义唯物辩证法要求我们看待事物要一分为二辩证来看, 但是在实际生活中, 大众对于 化学的态度还是处于非黑即白的简单认识层面上。很多新闻媒体对化学危害过分宣传, 夸大事实, 一些不具备科学素养的新闻工作者对自己并不熟悉的化学领域大谈特谈, 指点江山, 将化学塑造成 一个十恶不赦的恶魔形象。其中最引人瞩目的当属前央视主持人柴静 “自费” 拍摄的纪录片《穹顶 之下》, 在这部 103 分钟的纪录片中, 柴静将我国的化工产业贬低的一无是处, 是许多灾祸的源头。 由于她本人身份的特殊性, 这部纪录片在社会舆论中造成了巨大的影响力。很多群众对我国关于发 展大化工的顶端设计产生了质疑, 要求限制甚至关停这些企业和产业。但随后事情的发展却非常戏 剧化, “自费” 拍摄的背后是美国福特基金会下属机构 NRDC 支持的结果, 大量造假的数据, 海量 水军的评论都表明这件事本身绝不是简单的个人事件, 其中牵扯着中美两国之间的无形博弯。化学 是一个神魔同体的存在, 它既可以造福人类创造价值, 也可以危害社会造成灾难。化学会走向何方 完全取决于使用化学的人类本身, 大禹治水的智慧早已告诉我们逆境可以化作顺境, 挑战也可变为 机遇。面对化学, 我们既不需要过分崇拜, 也不必太过恐慌, 而这就需要化学科普为大家普及化学 知识, 提升大众的化学素养。 


\subsection{4 传播文化一一化学科普工作的天然属性}

化学作为一门自然科学, 从诞生起就开始创造物质财富和精神财富。化学影响着社会的发展, 相 应地社会也反过来作用于化学, 二者相辅相成相互促进, 推动文明的进步。从波义尔的《怀疑派化 学家》到道尔顿的《化学哲学新体系》再到拉瓦锡的《化学基础论》, 近代化学成就对哲学发展产生 了重大影响, 同样哲学思想的指导也为化学发展提供了强大的理论支撑 ${ }^{[7]}$ 。化学和人类的物质文明 和精神文明息息相关。中国人流行的茶文化、酒文化甚至是餐桌文化, 从某种程度上来看也属于化 学文化的一部分, 人们的衣食住行更是处处联系着化学文化。因此, 化学纪录片在传播化学知识的 同时, 自然而然也是对化学文化的一种宣传。

\section{3 启示与展望}

国外的化学纪录片在选题、策划、拍摄等方面都有可取之处, 值得我们学习。他们的科普纪录 片产业已经非常成熟, 能够创造丰厚的经济效益 ${ }^{[8]}$ 。这意味着科普纪录片能够自生血液, 自给自足, 失去国家财政的扶持也能顺利发展, 这是未来我们努力奋斗的目标。科普纪录片的重要意义不是简 单地创造物质财富, 更重要的是对大众精神层面的提升。科普纪录片肩负着传播正统的科学观、价 值观、文化观的光荣使命, 是主流思想的体现。纵观国内纪录片市场, 纪录片的类型还是以人文历 史居多, 科普类的纪录片相对较为稀少, 就算是国内比较脍多人口的几部精品科普纪录片, 相较于 国际顶尖水平的同类作品还是略有不足。今日之中国正处于百年未有之大变局的重要节点, 提升自 身文化软实力, 对外宣传中国文化, 讲述中国故事, 少不了中国纪录片的强力支持, 这要求我们的 科普纪录片能够在国内深厚的文化积淀中去粗取精, 在国外优秀的作品中去伪存真, 借鉴创新, 内 外结合, 创造出富有中国自身特色的科普纪录片。

如今, 媒体行业已经发生了翻天覆地的变化, 互联网的兴起催生出了许多新型产业, 各种视频 平台在此浪潮中水涨船高, 吸引了大量的流量和财富。传统的电视频道逐渐失去了对观众的吸引 力, 海量的自媒体应运而生, 在新媒体时代获得了一定的话语权, 其中也不乏科普类短视频 ${ }^{[9]}$ 。在 2020 年新冠肺炎疫情期间, 网络媒体使用直播和短视频的方式科普抗疫信息, 向全人类传授科学抗 疫的中国方案, 让世界感受到了中国共产党领导下的伟大的中国力量。新的态势要求我们做出新的 调整, 传统的纪录片行业也需要在互联网+的新常态下做出变革, 积极拥抱时代浪潮, 以壮士断腕的 决心自我革新, 从上到下, 从思想意识到拍摄宣传都能够有所突破, 这样才能拍摄出更加品质优良、 脍多人口的科普作品。

\section{参 考 文 献}

[1] 任远. 电视纪录片新论. 北京: 中国广播电视出版社, 1997: 3 .

[2] 张雅欣. 中国电视, 2005, No. 6, 42 .

[3] 张同道. 中国传媒大学学报, 2020, 42 (7), 109.

[4] 把科学普及放在与科技创新同等重要位置. [2016-06-02]. http://opinion.people.com.cn/n1/2016/0602/c1003-28405979.html

[5] 李厚金, 陈六平. 大学化学, 2020,35 (11), 8.

[6] 今日谈: 不忘来路才能更好前行. [2020-01-29]. https://baijiahao.baidu.com/s?id=1657019875276187104\&wfr=spider\&for=pc

[7] 郭瑞斌, 莫尊理, 李莉, 孟淑娟, 冯超. 化学教育, 2011, 32 (9), 93.

[8] 喻溟. 电影艺术, 2020, No. 3, 105.

[9] 张成军. 电视研究, 2013, No. 9, 59 . 